\title{
PERCURSOS NARRATIVOS EM EDUCAÇÃO
}

\section{MATEMÁTICA}

\section{Apresentação}

Necessitamos de uma linguagem para a experiência, para poder elaborar (com outros) o sentido ou a falta de sentido de nossa experiência, a sua, a minha, a de cada um, a de qualquer um.

Larrosa (2015, p. 67-68) ${ }^{1}$

O que tem mobilizado os educadores matemáticos para traçar seus percursos investigativos tomando as narrativas como inspiração teórico-metodológica? Seriam as narrativas uma linguagem para conversarmos sobre a educação matemática?

Parece-nos que esse tem sido um caminho promissor, para produzirmos nossas pesquisas, colocando-nos à escuta de estudantes e professores, como forma de darmos sentido às nossas experiências com o ensino e a formação do professor que ensina matemática. Como um ato político de valorizarmos as vozes daqueles que, historicamente, têm sido silenciados.

Temos assistido, nas últimas décadas, à ampliação do diálogo dos educadores matemáticos com o campo das narrativas - seja na perspectiva da História Oral, seja na do método (auto)biográfico. o primeiro artigo deste dossiê - Educação Matemática e estudos (auto)biográficos: um campo de investigação em construção -, de autoria de Adair Mendes Nacarato, Kátia Gabriela Moreira e Iris Aparecida Custódio - apresenta uma síntese interpretativa desse percurso, tomando o ano de 2010 como um marco, pois, pela primeira vez, a comunidade de educadores matemáticos, pertencente ao GT19 da Anped, através de tra-

1 LARROSA, Jorge. Tremores: escritos sobre experiência. Belo Horizonte: Autêntica, 2015. balho encomendado pelo GT, centra-se na discussão de narrativas na educação matemática, conforme sistematizado por Souza (2010). ${ }^{2}$

A partir desse marco, as autoras apresentam outros espaços científicos nos quais a temática das narrativas vem se ampliando. No cenário nacional, há grupos de pesquisa em universidades de vários estados brasileiros que têm se debruçado sobre esta opção teórica e metodológica. Evidências dessa ampliação se fazem presentes no volume de trabalhos que são submetidos a periódicos nacionais e internacionais e às edições do Congresso Internacional de Pesquisa (Auto)Biográfica (CIPA). Se considerarmos todas as edições do CIPA até 2018, há em torno de 100 trabalhos relacionados à educação matemática.

O texto de Marinéia dos Santos Silva e Heloisa da Silva - Movimentos das narrativas na Educação Matemática brasileira e o lugar da História Oral - ainda que não tenha como foco principal apresentar a retrospectiva das pesquisas na área, discute, a partir das investigações de grupos de pesquisa que estudam as narrativas na formação de professores que ensinam Matemática, como foi possivel compreender o movimento de entrada, apropriação e circulação das narrativas na comunidade acadêmica da Educação Matemática.

Não produzimos uma trajetória histórica sobre a inserção das narrativas nas pesquisas em Educação Matemática porque os textos de Nacarato, Moreira e Custódio e de Silva e Silva,

2 SOUZA, Elizeu Clementino de. Pesquisa narrativa, (auto)biografias e história oral: ensino, pesquisa e formação em Educação Matemática. Ciências Humanas e Sociais em Revista, v. 32, p. 1- 14, 2010. 
neste dossiê, o fazem. É inegável o quanto as pesquisas nessa temática vêm se ampliando e consolidando alguns grupos de pesquisa. Em especial, neste dossiê, estão presentes grupos de pesquisa que apresentaram seus trabalhos em todos os dossiês já publicados, bem como em eventos como o CIPA e as reuniões nacionais da Anped. Identificamos a presença dos grupos: Grupo História Oral e Educação Matemática (GHOEM - Unesp, Rio Claro); Grupo de Estudos e Pesquisa em Educação Matemática (GEM - UFSCar, São Carlos); Grupo de Estudos e Pesquisas em Educação Estatística e Matemática (GEPEEM, Universidade Cruzeiro do Sul, São Paulo); Histórias de Formação de Professores que Ensinam Matemática (Hifopem - Universidade São Francisco, Itatiba/SP); Grupo História da Educação Matemática em Pesquisa (HEMEP, UFMS, Campo Grande); Formação de Professores e Práticas Pedagógicas (PUC-Campinas); Grupo de Estudos e Pesquisas em Educação Matemática (GREPEM - UFJF); e Grupo de Pesquisa em Educação Estatística (EduEst - FURG). Sabemos da existência de outros grupos em que pesquisas narrativas e com narrativas na Educação Matemática são desenvolvidas, mas não estão representados neste dossiê.

Certamente, tal interesse se deve às possibilidades de explorar a historicidade, aspecto marcante das narrativas e das práticas pedagógicas, bem como a compreensão de práticas sociais relativas à Educação Matemática.

As narrativas, em suas múltiplas modalidades: histórias de vida de educadores, narrativas de trajetórias profissionais, narrativas de estudantes e adolescentes, narrativas de práticas, memoriais de formação, dentre outras, têm revelado as potencialidades como práticas de (auto)formação e de pesquisa, bem como revelado singularidades no âmbito da pesquisa educacional e contribuído para as diferentes compreensões sobre o ensinar e o aprender matemática, assim como sobre as di- mensões da profissão do professor que ensina matemática.

A organização de mais um dossiê sobre narrativas e educação matemática representa outro momento de sistematização e divulgação dessas múltiplas possibilidades de abordagem teórico-metodológica. Desde os primeiros trabalhos de sistematização do campo de investigação, duas tendências são identificadas: trabalhos vinculados à História Oral e ao método (auto)biográfico. Neste dossiê não foi diferente. Essas duas perspectivas se fizeram presentes.

No conjunto de quinze artigos que compõem este dossiê, doze deles centram-se na formação do professor e/ou do formador do professor que ensina matemática e, desses, seis referem-se às narrativas das próprias pesquisadoras, formadoras de professoras. Isso nos remete a refletir sobre a importância do pesquisador não apenas se colocar à escuta dos pesquisados, mas de também refletir sobre a sua trajetória, as escolhas que fez e porque as fez, como se tornou professor e formador.

Organizar a sequência de artigos que compõem um dossiê nem sempre é tarefa fácil; os agrupamentos por temáticas, na maioria das vezes, partem da interpretação dos organizadores. A organização aqui realizada tomou como eixo norteador as temáticas apresentadas; no entanto, ela pode ser contestada. Identificamos cinco eixos temáticos: sistematização da produção na área de narrativas e educação matemática; narrativas de si ou self study; interfaces entre narrativas e História Oral; trajetórias profissionais construídas por meio de memoriais de formação e/ou pesquisa narrativa; e narrativas da formação inicial do professor que ensina matemática.

0 texto que abre este dossiê, como mencionado anteriormente, apresenta o movimento de produção nacional dos educadores 
matemáticos nesse campo de investigação, no período de 2010 a 2018. O corpus de dados para análise é constituído das publicações nos anais de cinco edições do CIPA e de quatro edições do GT19, nas reuniões anuais da Anped, além de periódicos qualificados em Educação e Educação Matemática. Adair, Kátia e Iris apontam para a diversidade dos modos de produção com e sobre narrativas e a importância dos cuidados éticos e teórico-metodológicos na pesquisa com essa temática.

Na sequência, são apresentados os artigos cujas autoras narram suas próprias experiências. $O$ artigo de Signe E. Kastberg, Elizabeth Suazo-Flores e Sue Ellen Richardson, Mathematics Educator Teacher Stories, centra-se nas narrativas das formadoras de professoras, na abordagem metodológica do self study. Elas partem do princípio de que o formador, para mobilizar os futuros professores a produzirem suas autobiografias, também precisa narrar suas histórias, com suas experiências e visões sobre o ensino de matemática. Os trabalhos de John Dewey e Carl Rogers e as reflexões por elas produzidas constituem os artefatos de suas práticas de ensino. Segundo elas, o potencial das histórias de professores pode ser interpretado como uma contranarrativa para o papel dos programas de formação de professores nos Estados Unidos. Nessas novas narrativas, formadores e futuros professores são vistos como aprendizes em seus modos práticos de aprender.

Numa abordagem narrativa similar, Dana Christine Cox, no texto Toward an Empathetic Understanding of Scholarship, parte de suas próprias experiências, para questionar a aquisição e a geração de conhecimentos matemáticos e pedagógicos, quando se tem uma situação privilegiada de bolsista na pós-graduação. Defende uma abordagem metodológica mais empática do conhecimento acadêmico em educação matemática e aponta para as con- tradições existentes na universidade. Questiona as condições de produção do trabalho acadêmico, como os rascunhos não são discutidos e valorizados e aponta para a importância da escrita colaborativa. A autora faz três recomendações: abordar a necessidade de rascunhos na estrutura acadêmica existente; reimaginar os papéis do pesquisador dentro do sistema de revisão por pares; e adotar metodologias mais empáticas, que permitam que as vozes humanas sejam centradas na pesquisa sem redução ou interpretação. Diz ela: "Não é mais aceitável acreditar que o olhar e a interpretação de um pesquisador objetivo são tão válidos quanto a perspectiva em primeira mão dos participantes".

Gabriela Félix Brião, no texto Possibilidades de autoformação docente em uma jornada narrativa, também se apoia na metodologia narrativa, na perspectiva do self study, e analisa sua trajetória como professora de matemática e formadora de professores. 0 texto é resultado de sua pesquisa de doutorado na qual analisou cinco percursos formativos. Contou com vários artefatos para a produção e a análise dos dados: audiogravações, e-mails, audiogravação do exame de qualificação, assim como as interferências de companheiros de jornada. Segundo ela, sua opção foi por uma apresentação insubordinada criativa, com uma postura epistemológica frente à pesquisa de si mesma. Ela busca responder à pergunta: como nos tornamos os professores que somos hoje?

No texto $A$ análise narrativa como possibilidade de uma linguagem para experiência, as autoras Adriana Barbosa de Oliveira, Marilena Bittar e Luzia Aparecida de Souza apresentam o percurso narrativo desenvolvido em torno de uma pesquisa de doutorado, que teve Adriana como autora e Marilena e Luzia como orientadoras. As autoras narram suas experiências diante da trajetória da pesquisa sobre as percepções de estudantes de cursos de Licencia- 
tura em Matemática, acerca de sua formação para atuar na prática docente. A pesquisa teve seu foco teórico e analítico totalmente transformado no processo e elas narram como isso afetou e transformou as três pesquisadoras. Elas utilizam a análise narrativa e os conceitos de experiência e alteridade de Jorge Larrosa e Carlos Skliar.

Thays Rodrigues Votto, Karla Priscila Schreiber e Mauren Porciúncula Moreira da Silva, no texto $O$ caminhar acadêmico e profissional de duas professoras em Educação Estatística, apresentam as narrativas de experiências de duas das autoras do texto. Tomando o espaço tridimensional da pesquisa narrativa, elas analisam suas trajetórias, a partir do encontro que tiveram com as temáticas estudadas, na pós-graduação. Traçam e analisam suas autobiografias como professoras e pesquisadoras no campo da Educação Estatística. A análise possibilitou compreender o processo de formação contínua, ao longo da vida, como as experiências com os outros, as interações com os pares e os professore e colegas vão direcionando os sujeitos para uma determinada área de atuação. No caso delas, essa trajetória culminou na pesquisa científica no campo da Educação Estatística.

No último texto desse eixo, Andréa Souza de Albuquerque e Tadeu Oliver Gonçalves, ao indagarem de que modo reflexões propostas em relatos autobiográficos de docentes podem contribuir para explicar e compreender a trajetória profissional deles, apresentam o artigo - Os desafios de ser e estar na profissão docente: reflexões de uma professora sobre sua trajetória profissional. Através da sua narrativa, a autora Andréa reflete sobre o seu processo de construção da identidade profissional, marcado "pelo tempo e pelas relações estabelecidas, pelos sabores e dissabores da docência". Na tessitura do narrado, ela compreende seu processo formativo e encontra significado pelas escolhas feitas ao longo da formação e da carreira.

A interface entre as narrativas e História Oral discutida poderá ser acompanhada na leitura do artigo - Explorando o conceito de ideologia: uma tentativa de aproximação entre Hermenêutica de Profundidade e História Oral -, de autoria de Kátia Guerchi Gonzales e Antônio Vicente Marafioti Garnica e de Movimentos das narrativas na educação matemática brasileira e o lugar da história oral, já mencionado anteriormente. Os autores desses textos são membros do Grupo História Oral e Educação Matemática (GHOEM), vinculado à UNESP, que desde os anos 2000 tem mobilizado seus participantes ao diálogo com diferentes áreas do conhecimento e se apropriado da História Oral por elas desenvolvida, ao estudar relações entre o ensino e a aprendizagem matemática.

Kátia e Vicente, através de dois referenciais teóricos-metodológicos - História Oral e Hermenêutica de Profundidade - apresentam uma discussão sobre as ideologias que cercam as Licenciaturas de Ciências - Habilitação em Matemática, desenvolvidas em regime parcelado no Mato Grosso do Sul. Discutem como a conexão desses referenciais, mobilizados a partir de memórias de professores, administradores e ex-alunos envolvidos desde a implantação das Licenciaturas Parceladas até sua extinção, permitiram-lhes, por meio do diálogo entre fontes de diversas naturezas, perceber relações estruturadas socialmente. Para compreender as mudanças sociohistóricas ocorridas, eles se apoiaram no conceito de ideologia, mobilizaram a Hermenêutica de Profundidade, para a compreensão das Licenciaturas Parceladas, e a História Oral (por meio da produção de narrativas específicas), para ouvir e registrar os modos subjetivos como as pessoas envolvidas com essas Licenciaturas atribuem significado à emergência da formação docente. 
Marinéia e Heloisa apresentam a compreensão sobre a "entrada e a movimentação das narrativas na Educação Matemática, bem como sobre o lugar da História Oral nesse movimento". A partir dos princípios metodológicos da História Oral, as autoras asseveram que as pesquisas em Educação Matemática com História Oral se diferenciam das demais pesquisas nessa área, que abordam narrativas, pelo compromisso assumido com a historiografia. Nesse diálogo, as autoras pontuam tratar-se de diferentes movimentos de investigação. As narrativas são o ponto de partida nas compreensões históricas envolvendo História Oral e Educação Matemática, em que se busca criar nossos discursos sobre as culturas de matemática e a educação matemática. A perspectiva analítica sob o viés histórico, argumentam as autoras, "ao mesmo tempo em que demonstra imparcialidade por evidenciar as diferentes versões históricas, apresenta também uma parcialidade ao expor sua própria versão histórica".

A temática trajetórias profissionais construídas por meio de memoriais de formação e/ou pesquisa narrativa está presente em três artigos. Flávia Cristina Figueiredo Coura, no artigo A pesquisa narrativa na análise do desenvolvimento profissional do formador de professores de matemática socializa a interpretação da história de vida de uma formadora de professores de matemática. A pesquisa narrativa constituiu-se no caminho para recontar essa história e permitiu compreender o desenvolvimento e as mudanças. Ao considerar o desenvolvimento profissional da formadora, a autora assumiu a intencionalidade e a importância da agência dessa formadora, concentrou nela o foco da pesquisa e integrou a sua biografia à investigação. Ela reconhece a importância da trajetória pessoal de vida e de formação da formadora em seu desenvolvimento, em um processo diacrônico, pois considera a história da pessoa, as relações que estabelece com o que viveu, o presente e suas expectativas futuras. Identificou experiências que influenciaram o desenvolvimento profissional da formadora, que representam vias de transformação pessoal e que contribuíram para a constituição de sua profissionalidade.

O texto Escolhas, vivências e circunstâncias no memorial de formação de professores de Matemática, de lara Letícia Leite de Oliveira, Rosana Areal de Carvalho e Fernanda Aparecida Oliveira Rodrigues Silva, apresenta compreensões de trajetórias formativas de professores de matemática através de suas histórias de vida narradas em memorial. Interpretadas à luz da Análise de Convergências e Singularidades, mostram que o movimento de tornar-se professor é permanente, circunstanciado por diversas vivências, em vários cenários. 0 texto narrado como uma viagem de trem traz histórias mineiras... A metáfora da viagem de trem guiou a dissertação de mestrado de lara, desenvolvida na UFOP, sob orientação de Rosana e Fernanda. As autoras tomam, aqui, a vida como uma viagem de trem e colocam-se como maquinistas, ao traçarem itinerários da dissertação como um diário dessa viagem investigativa que conduz o leitor a viajar nesse trem.

Nathalia Tornisiello Scarlassari e Celi Espasandin Lopes, em Narrativas de professores de matemática em formação contínua, apresentam a trajetória profissional de três professores de matemática da Educação Básica que participam de um grupo de estudos colaborativo. 0 diferencial desse grupo, que focaliza a investigação matemática para a abordagem da Educação Estatística, é que os participantes assumem papéis ativos na busca de soluções para problemas de contextos reais. Mais do que um lugar de formação contínua, a narrativa de si desses professores revela que o grupo é onde eles se sentem seguros para experimentar, para desenvolver práticas criativas 
que dialogam com a realidade em que atuam e sentem-se reconhecidos pelo trabalho realizado. Nesse espaço de confiança, narram suas trajetórias e práticas, socializam fazeres profissionais, diversidade de opiniões que contribuem para o enriquecimento e o redimensionamento de práticas profissionais.

Os três últimos artigos desse dossiê focalizam "narrativas na formação inicial do professor que ensina matemática". Jane Maria Braga e Reginaldo Fernando Carneiro, em - $O$ que dizem as narrativas de estudantes de pedagogia sobre sua formação matemática? -, fazem das narrativas de si instrumento de formação e de investigação e apresentam as percepções de estudantes de Pedagogia sobre sua formação matemática na Educação Básica e na formação em curso, após participarem de uma disciplina com foco na matemática, quando retomam a primeira narrativa e refletem a respeito do processo formativo vivido na universidade. Os autores argumentam que as escritas de si, em momentos distintos do curso, fazem aflorar discussões sobre diferentes saberes, próprios da docência, que se relacionam, coexistem e favorecem concepções sobre o ensino de matemática. Acioná-los, desenvolvê-los e ampliá-los é o objetivo do exercício escrito, e serviu de base para o artigo aqui apresentado. O estudo revelou um número significativo de narrativas que apontam para uma matemática escolar sem significado, pautada na repetição, na memorização. Com a vivência no curso de Pedagogia, há indícios de novos olhares sendo construídos. Tomar consciência das marcas deixadas pela matemática na formação inicial faz-se promissor para o processo formativo no curso de Pedagogia.

No texto Narrativas de formação de professores de matemática sobre os Estágios Supervisionados, de Maria das Graças dos Santos Abreu, Maria Auxiliadora Bueno de Andrade Megid e Alessandra Rodrigues de Almeida dia- logam com as experiências vividas por licenciandos em Matemática, a partir da unidade curricular Estágios Supervisionados, e como tais estágios estão organizados no curso de Licenciatura. As autoras, docentes do referido curso, indicam que desenvolvem um trabalho buscando romper com a lógica estrutural do pensamento vigente de que a área em que se situa essa disciplina é 'dura', dificil e rígida, o que pode sugerir que o profissional de matemática não seja sensivel aos problemas educacionais. Assim, dentre as diversas ações formativas, adotam a narrativa de vida e formação, como um relatório final de trabalho, que é disparadora de um processo reflexivo dos graduandos sobre si e sua formação profissional. Neste artigo, as pesquisadoras trazem trechos de narrativas, centradas nas memórias e nos registros de dois licenciandos, que expressam dilemas e angústias com o trabalho e a realidade escolar, ressaltam a tomada de consciência do preparo acadêmico e da transição de aluno para professor.

Por fim, o texto Conhecendo mais sobre a ludicidade, formação de professores e ensino de matemática no curso de Pedagogia da UFSCar, de Américo Junior Nunes da Silva e Cármen Lúcia Brancaglion Passos, abre ao leitor um diário sobre a matemática e a ludicidade na formação inicial de professores dos anos iniciais. Em diálogo com o leitor, o que as estudantes revelaram, em seus diários e nas entrevistas narrativas a respeito das experiências vividas no curso, está entrelaçado ao estudo teórico dos documentos históricos de sua criação e da atual Proposta Pedagógica. Neste "diário", a tridimensionalidade está na análise e na interpretação, envolve a temporalidade (diacronia), as interações pessoais e sociais e o lugar (cenário) onde se situa o fenômeno a ser investigado e narrado. Revela mais do que o modo como o ensino da matemática e a ludicidade estão articulados no curso. Re- 
vela que deixou marcas. A partir da prática da escrita do diário e da constante interlocução na formação, algumas estudantes assumiram a prática de escrita em diários, após o término da pesquisa, como algo que poderá fazer parte do seu fazer pedagógico e do pensar a sua formação.

Se, em dossiês anteriores relacionados à Educação Matemática e narrativas, foi identificada uma polissemia da temática, neste, constatamos uma sintonia: doze textos abordam as vozes de professores, futuros professores, professores formadores e pesquisadores. Isso pode ser o indício sobre o quanto a temática das narrativas provoca a sensibilidade do formador-pesquisador, pois não basta colocarse à escuta do professor, é preciso expor-se, narrar suas experiências e suas trajetórias. Constatamos que isso tem sido presença nas dissertações e teses: o memorial do pesquisador, no qual ele narra como o seu tema de investigação está imbricado a sua trajetória profissional. No entanto, poucos são os artigos em que o pesquisador, principalmente o orientador, se expõe. Nesse sentido, esse dossiê é um avanço em relação aos anteriores. Estaríamos encontrando uma linguagem para narrar nossas experiências?

Essas foram algumas de nossas percepções e interpretações. Ao darmos o texto a ler, cada leitor produzirá as suas interpretações. Esperamos que este dossiê possa ampliar o debate sobre os percursos narrativos em Educação Matemática e incentivar novos pesquisadores.

Campinas, São Paulo, outono de 2019

Adair Mendes Nacarato Universidade São Francisco

Cármen Lúcia Brancaglion Passos Universidade Federal de São Carlos

Celi Espasandin Lopes

Universidade Cruzeiro do Sul/Universidade Cidade de São Paulo 